\title{
Fatigue risk management for cabin crew: the importance of company support and sufficient rest for work-life balance-a qualitative study
}

\author{
Margo J. VAN DEN BERG ${ }^{1}$ *, T. Leigh SIGNAL ${ }^{1}$ and Philippa H. GANDER ${ }^{1}$ \\ ${ }^{1}$ Sleep/Wake Research Centre, Massey University, New Zealand \\ Received November 9, 2018 and accepted April 4, 2019 \\ Published online in J-STAGE April 17, 2019
}

\begin{abstract}
Knowledge about cabin crew fatigue associated with ultra-long range (ULR) flights is still limited. Current ULR scheduling for cabin crew is therefore predominantly based on flight crew data. Cabin crews' views on fatigue, and their strategies for mitigating it, have seldom been sought. To better understand the causes and consequences of cabin crew fatigue, semi-structured focus group discussions were held. Thematic analysis was undertaken with data from 25 cabin crew. Participants indicated that the consequences of fatigue are twofold, affecting 1) cabin crew health and wellbeing and 2) safety (cabin, passenger and personal) and cabin service. While the primary causes of fatigue were sleep loss and circadian disruption, participants also identified other key factors including: insufficient rest, high workload, the work environment, a lack of company support, and insufficient fatigue management training. They highlighted the importance of sufficient rest, not only for obtaining adequate recovery sleep but also for achieving a work-life balance. They also highlighted the need for company support, effective communication, and management's engagement with cabin crew in general. We recommend that priority is given to fatigue management training for cabin crew, which may also enhance perceived company support and assist with achieving a better work-life balance.
\end{abstract}

Key words: Fatigue risk management system (FRMS), Commercial aviation, Work-life balance, Focus groups, Thematic analysis

\section{Introduction}

The aviation industry offers $24 / 7$ service, which creates a number of challenges for cabin crew. They often

experience irregular schedules, long duty periods, circadian rhythm disruption, sleep loss and high workload, which have all been shown to be contributing factors to cabin crew fatigue ${ }^{1-9)}$.

For example, a field study which monitored the sleep of

*To whom correspondence should be addressed.

E-mail: m.j.vandenberg@massey.ac.nz

(C)2020 National Institute of Occupational Safety and Health
202 cabin crew during a 3-4 wk period showed that they obtained an average of $6.3 \mathrm{~h}$ sleep on free days, $5.7 \mathrm{~h}$ of sleep on work days, and even less when operating international flights $(\text { mean }=4.9 \mathrm{~h})^{10}$. However, recently consensus has been reached that adults require $7-9 \mathrm{~h}$ of sleep per day for maintaining optimal functioning and health ${ }^{11,12)}$.

Sleep loss occurs not only as a consequence of working irregular hours, but also due to circadian rhythm disruption caused by rapid travel across multiple time zones ${ }^{13)}$. Jet lag has been associated with sleep disturbance during layovers and post-trip at home ${ }^{7,14-18)}$.

It is therefore not surprising that cabin crew experience work-related fatigue. In a large-scale survey with 9,180 
cabin crew, $84 \%$ reported being fatigued while on duty, of which $71 \%$ reported that their safety-related performance was affected, and $52 \%$ reported that they had 'nodded off' while working on a flight ${ }^{1}$.

Considering the important role of cabin crew in maintaining passenger and cabin safety, cabin crew fatigue and its associated risks needs to be managed carefully.

Traditionally, fatigue risk has been managed through prescriptive limits on maximum duty durations and minimum rest durations within and between duty periods. This 'one-size-fits-all', single-layer defensive strategy is adequate for some type of operations, but it does not take into account all known causes of fatigue that can lead to impaired performance ${ }^{19,20)}$.

Fatigue Risk Management Systems (FRMSs) are a relatively new approach to improving safety and increasing operational flexibility. The International Civil Aviation Organization (ICAO) has defined FRMS as "a data-driven means of continuously monitoring and managing fatiguerelated safety risks, based upon scientific principles and knowledge as well as operational experience that aims to ensure relevant personnel are performing at adequate levels of alertness". Advances in sleep science are integrated with safety science using similar processes and procedures to an airline's Safety Management System (SMS) for managing other types of hazards ${ }^{21)}$. ICAO's FRMS guidelines, which are applicable to both flight crew (i.e. pilots) and cabin crew, were developed with the advent of newer aircraft able to fly more than $16 \mathrm{~h}$ non-stop, thus exceeding the maximum limits of traditional flight and duty time regulations. To manage the fatigue risk associated with these ultra-long range (ULR) flights, defined as flight operations between a specific city pair in which at least one of the flight sectors regularly exceeds $16 \mathrm{~h}$ planned flight time ${ }^{22)}$, airlines are usually required to put in place an FRMS.

Current ULR scheduling and FRMS processes for cabin crew are predominantly based on flight crew data, as information on cabin crew fatigue associated with ULR flights is very limited ${ }^{23}$ 24). Hence, little is still known about how well current FRMS processes work for cabin crew. As an example, the main fatigue mitigation for ULR flights is to provide in-flight breaks and crew rest facilities in which crewmembers can obtain sleep. However, due to the requirement for all cabin crew to be awake for meal services, they have less time available for inflight rest compared to flight crew. In addition, in many countries the regulatory requirements for on-board rest facilities are less rigorous for cabin crew than for flight crew.
Cabin crew workload is also considerably different in nature from that of flight crew. Cabin crew duties include more physical tasks and walking. In addition, passenger demands, medical incidents, and turbulence, can significantly add to their workload ${ }^{1,25-28)}$. This may have implications for the rest requirements for cabin crew. However, current scheduling does not take into account the relationship between workload and the high levels of fatigue frequently experienced by cabin $\mathrm{crew}^{2}$.

Findings from a field study conducted with cabin crew flying a ULR trip between Johannesburg and New York showed that overall, the fatigue mitigation strategies used for flight crew on this route were also effective for managing cabin crew fatigue. However, large individual differences were observed in the amount of sleep obtained by cabin crew, not only in flight, but also at home and on layover ${ }^{23)}$. Furthermore, compared to flight crew flying this same route, cabin crew obtained on average less sleep pre-trip and in flight, and a larger proportion experienced sleepiness while on duty ${ }^{29)}$. This suggests that a greater diversity of personal, environmental, and/or work-related factors may have influenced their sleep, which warrants further investigation in order to develop better recommendations for improving fatigue management for cabin crew $^{23)}$.

Importantly, fatigue is affected (negatively or positively) by activities outside of work as well as by work-related ones and can be considered a 'whole of life issue"20). As such, fatigue management must be a shared responsibility between the employer and employee. To be able to reduce or mitigate fatigue, the causes and consequences of fatigue need to be understood. However, cabin crews' views on fatigue and their strategies for mitigating it, have seldom been sought.

The present study aimed to better understand cabin crews' views on fatigue, and how it might affect safety and their job performance, particularly in the context of ULR operations. Because the experience of fatigue is widely shared among cabin crew, semi-structured focus group discussions were considered the best choice for this purpose. Through the process of group interaction, these discussions can generate a large volume of enriched data to obtain a greater variety of views, opinions and experiences and were therefore preferred over individual interviews, or quantitative methods such as surveys $^{30,31 \text { ). }}$.

Specifically, cabin crews' perspectives were sought on the following: the causes of cabin crew fatigue at home and at work; the consequences of cabin crew fatigue at home and at work; how their fatigue is currently managed 
at home and at work and what could be changed to reduce their fatigue.

As ULR operations continue to expand in the aviation sector, this study is, to the best of our knowledge, the first to seek the perspectives of cabin crew with ULR experience.

\section{Subjects and Methods}

Semi-structured focus group discussions were used to obtain a variety of views, opinions, and experiences from participating cabin crew. The study was reviewed and approved by the Massey University Human Ethics Committee: Southern A (Application 13/45).

\section{Subjects}

All cabin crew who had flown the Johannesburg-New York ULR route (average outbound flight duration $=15.9 \mathrm{~h}$, inbound $=14.7 \mathrm{~h}$ ) were eligible to participate (total potential participants around 1,500 ). The aim was to conduct at least three focus groups with 8-10 participants each. Cabin crew were required to respond to an advertisement in the company's communication channels within a set time period, so that they could be scheduled to ground-based duty on the dates that focus groups were to be run. Of the 33 crewmembers who volunteered, 27 could be scheduled to ground duty and were assigned to one of three focus groups (group size of 9). One crewmember did not attend, leaving 26 participants. As per ethical requirement, participants had the right to withdraw from the study either during the session or upon receipt of the transcript. They were not required to provide a reason for this.

Of the 26 participants, one withdrew his/her data after reviewing the transcript. The results of the thematic analysis are therefore based on data from 25 participants.

Written consent was obtained prior to the start of the focus group discussion.

\section{Procedure}

Focus group discussions were scheduled across two consecutive days (20-21 February 2014) in a classroom at the airline's head office. A gift voucher (ZAR500) was offered before the start of the discussion as remuneration for participants' time to review their contribution in the transcript and for foregoing allowances associated with flying duty.

Each focus group discussion was facilitated by the first author and a research assistant. The first author, a PhD student currently working on the topic of fatigue risk management systems for cabin crew, has previous field research experience on the topic of fatigue management in flight crew and personal experience with shift work. She did not have a direct relationship with the participants and was not acting on behalf of the airline. The research assistant was a fellow cabin crewmember employed at the airline and knew some of the participants, but did not hold a position of authority.

Prior to the start of the focus group discussion, participants were asked to complete a demographic questionnaire with information on age, gender, and work experience. The interview script included a brief introduction to reiterate the purpose of the study and the participants' right to withdraw at any time. Participants were also given the opportunity to ask any further questions before the audio recording was started. The discussion was preceded by a quick warm-up question in which each participant was invited to introduce him/herself. Eight key questions (Table 1), formulated by the research team utilizing their significant experience of fatigue in aviation and FRMS, were used to guide the discussion and were displayed as visual prompts on a poster. These questions were designed to act as a memory aid for the group moderator, assist in managing the discussion around the studied topic, as well as ensuring consistency in questioning across the different focus groups ${ }^{30}$. Since no new issues were raised during the third focus group discussion, no additional focus groups were undertaken.

Table 1. Questions guiding the focus group discussion

\begin{tabular}{ll}
\hline Question 1 & When you are at home, what makes you fatigued? \\
Question 2 & When you are at work, what makes you fatigued? \\
Question 3 & How does fatigue affect you, when you are at home? \\
Question 4 & How does fatigue affect you, when you are at work? \\
Question 5 & Are there safety-related tasks at work that are affected by your fatigue? \\
Question 6 & How do you currently manage your fatigue at home? (what strategies do you use to cope, countermeasures) \\
Question 7 & How do you currently manage your fatigue at work? \\
Question 8 & If you think that fatigue is a safety concern in flight, what do you think could be changed for cabin crew? \\
\hline
\end{tabular}




\section{Data analysis}

Audio recordings were transcribed verbatim by an experienced staff member of South African nationality at the Sleep/Wake Research Centre. Each data extract includes a reference to its source (group number, ID). Where surplus or irrelevant information was excluded from a quote, the exclusion was denoted by [...]. Pauses were denoted by '...' and words that were spoken with strong emphasis were underlined. Transcripts were crosschecked against the audio recordings by the researcher, corrected as required, and then anonymized. Participants were given the opportunity to check, edit or withdraw their contribution and their written approval was sought to have their data included in the analysis.

To situate the present research within the existing knowledge of fatigue risk management ${ }^{21,32)}$, a pragmatist approach was adopted, which is a practical and applied research philosophy focused on producing 'real-world' knowledge that is solution-focused ${ }^{33)}$. Thematic analysis was undertaken using a 6-phase iterative process described by Braun and Clarke ${ }^{34)}$. Coding and theme development were undertaken using NVivo 10 (QSR International, Melbourne, Australia). To obtain a degree of verification, member reflections ${ }^{35)}$ were sought by giving participants the opportunity to comment on the findings.

\section{Results}

The three groups were very similar in terms of age, gender, crew position, work experience, and average work hours per month (Table 2). The proportion of males $(66-77 \%)$ in this study was considerably higher than the proportion of male cabin crew working at this company at the time (about 34\%). In Group 1, but not Groups 2 and
3, the majority of participants had taken part in a previous ULR validation field study ${ }^{23)}$. All participants had ULR experience and had received fatigue management training as required prior to commencing ULR flying.

There was general consensus that cabin crew fatigue is inherent to the nature of the work: "The nature of this job in itself will have a lot of fatigue [...] it is an international airline so it will travel at the wrong time, so that is the nature of the job" (Group 2, J).

The consequences of fatigue were shown to be twofold for cabin crew. Firstly, there were various effects on health and wellbeing, including the inability to function at home on the first day after an international flight, weight increase, and a lowered immune system increasing the likelihood of getting sick and/or becoming unfit to fly as a result of ill-health: "So, you come back to work with a compromised immune system and you are expected to work long hours. You're about to get tired, your immune system cannot take it, your mind, your body just shuts down" (Group 3, D). Secondly, effects on safety and service were reported, resulting from increased irritability, decreased alertness, forgetfulness, and performance changes, as well as falling asleep uncontrollably. Although it was said that their safety training and working as part of a team enabled fatigued cabin crew to handle emergency situations, there were nevertheless concerns about safety being compromised: "and also I am concerned in an evacuation if you needed to do an evacuation, if $90 \%$ of us are well rested that $10 \%$ are still in need, we need them to be alert but if they are not, it might not be as fast as effective as it would have been if we were all well rested. So those things have not happened yet, but they can happen. So they need to look into making sure that we have as much rest as possible before, during and after the flight" (Group 3, A). Not

Table 2. Demographic information by group

\begin{tabular}{|c|c|c|c|c|}
\hline & & Group 1 & Group 2 & Group 3 \\
\hline \multicolumn{2}{|c|}{ Age (mean; range) } & $40(29-62)$ & $39(33-50)$ & $41(24-52)$ \\
\hline \multirow[t]{2}{*}{ Gender } & Male & 6 & 7 & 6 \\
\hline & Female & 3 & 2 & 2 \\
\hline \multirow[t]{3}{*}{ Crew position } & Cabin crew & 6 & 6 & 5 \\
\hline & Purser & 2 & 1 & 1 \\
\hline & Senior Purser & 1 & 2 & 2 \\
\hline \multicolumn{2}{|c|}{ Work experience (mean; range) } & $16(7-43)$ & $13.5(8-20)$ & $16.5(4-30)$ \\
\hline \multicolumn{2}{|c|}{ Average work hours per month (mean; range) } & $110(90-133)$ & $120(90-120)$ & $120(100-140 *)$ \\
\hline \multicolumn{2}{|c|}{ Years ULR experience (mean; range) } & $2(1-3)$ & $3(1-3)$ & $3(1.4-4 * *)$ \\
\hline \multicolumn{2}{|c|}{ Took part in ULR field study***: Yes } & 7 & 3 & 3 \\
\hline \multicolumn{2}{|c|}{ Number of participants } & 9 & 9 & 8 \\
\hline
\end{tabular}

* Excludes 1 outlier (27 h); ** excludes 1 outlier (13 yr); *** van den Berg et al., 2015 
Fatigue Mitigation Strategies for Cabin crew

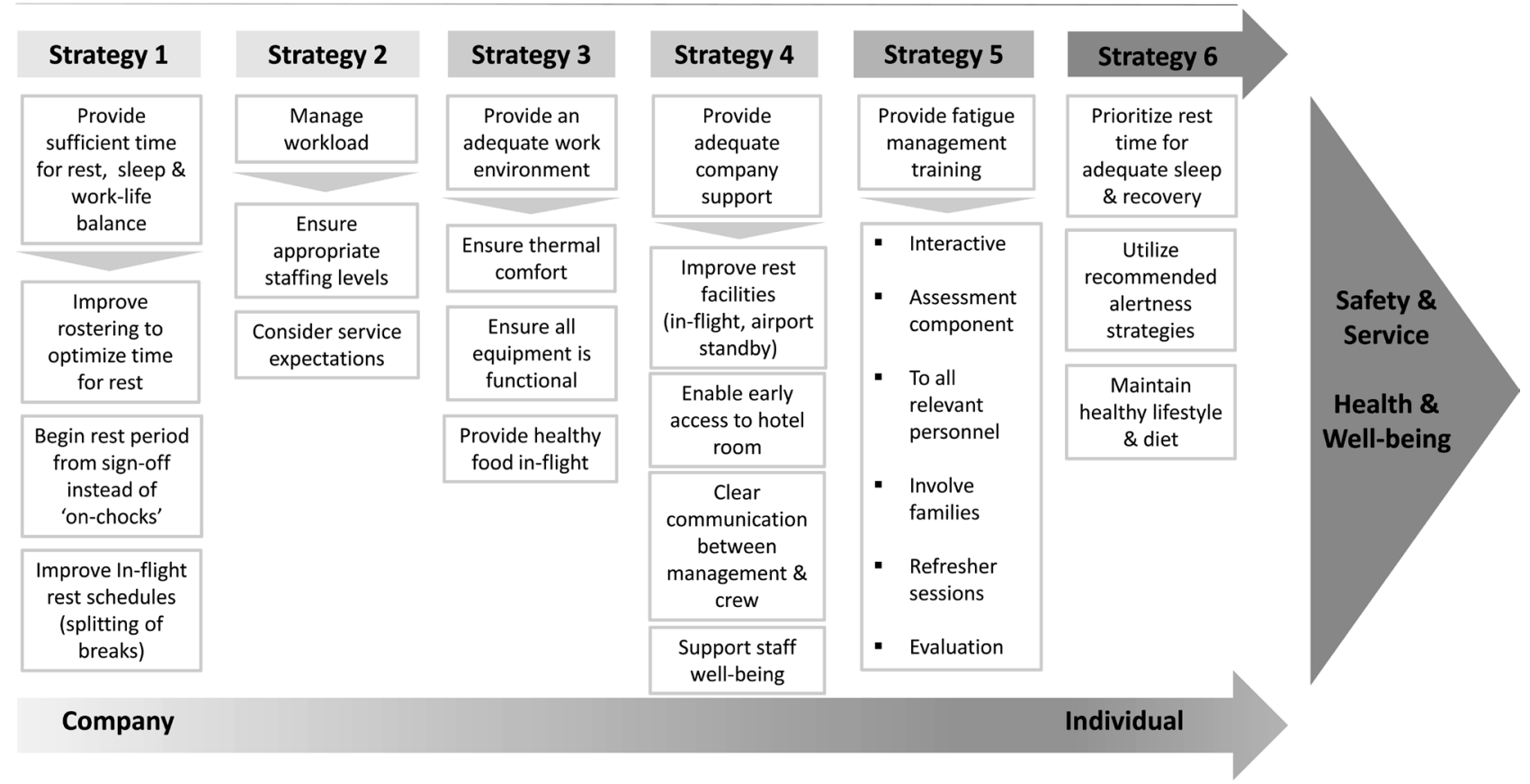

Fig. 1. Fatigue mitigation strategies for cabin crew at company and individual level (modified from Moore-Ede, 200958).

only were participants concerned about safety at work, but also driving home, with several reporting that they had fallen asleep.

Many factors contributing to fatigue were identified, often in conjunction with suggestions for changes to reduce it. The themes are described in the following sections and the recommended strategies associated with each theme are summarized in Fig. 1.

\section{Insufficient rest}

When participants talked about rest, this usually included sleep but also time for relaxation. Insufficient rest was considered a significant cause of fatigue attributed to several factors. Firstly, rest between duty periods starts from 'on-chocks' when the aircraft's engines are shut down, but cabin crew duties continue until the passengers are deplaned. "They give you minimum rest in terms of rest like $12 \mathrm{~h}$, it does not start from time of sign off. It starts from chocks. By the time you get home you have 10, 9 or $8 h$ " (Group 1, D).

Secondly, participants indicated that, although the minimum rest requirements may be sufficient for recovery from sleep loss, they are not sufficient for having a normal life at home: "I just think that when you get home, even if it is not always possible, try and take a nap [...] it is different for everybody, but you really make the best of your off days.
Like F says, you have things to do, you have got a life and you also have to rest, so you try and incorporate everything into two days. Two days is not enough for your life, because your life is not just flying, you know" (Group 3, A).

While some participants stated that they would prioritize sleep, others indicated that there was generally a tradeoff between sleep and other activities in the limited time available. Both male and female participants indicated that they attend to family and domestic responsibilities at home during the day. With these competing demands, family could also become a source of stress: "The other thing I definitely say is stress, the stress we get from our families, you know. You have come back from overseas and your son had a volleyball game and then they start blaming, but ... you know this job that you do, you can't even go to your son's activities and then to think of that, yeah, it does affect you" (Group 1, H).

Insufficient rest was also linked to several other factors, particularly rostering (i.e. the scheduling of work and rest), which participants viewed as the primary cause of the cumulative effects of sleep loss and circadian disruption. Specific aspects of the roster that they considered fatiguing included the combination of short-haul, long-haul and ULR flights, the limited number of days off before and after trips, and the irregular, and long work hours: "I think the major, major, major problem here is the scheduling, 
the rostering of the flights that's the major thing. Like, for example, you cannot be signing on at 4.45 in the morning and then knocking off at 5 in the afternoon, you can sign in at 4:45 and then knock off at 9 or 10 am, that you could manage just fine, as like B said, you are fatigued. So the major issue is rostering, if they could get that right" (Group 2, H). Roster changes were the most frequent suggestions for improvement. These included maximizing rest breaks between duty periods by changing the combination of flights, reducing the number of successive 'hectic' flights to reduce their cumulative effects, shortening very long turnaround times to reduce long duty days, and reducing the number of work hours per month.

Participants also raised issues with the crew rest facilities and timing of scheduled breaks (relative to their body clock) affecting sleep during long-haul and ULR flights. On short-haul duty days, time for rest could be very limited when turn-around times were very short. Positive comments were made about the Johannesburg-New York ULR trip having a day off before the trip, the splitting of in-flight rest breaks to enable at least one break to coincide with a more favourable circadian time for sleep, and the option of an additional rest in a seat on the longer outbound leg. However, participants queried why the shorter inbound leg was not treated as ULR for managing the fatiguing effects of the trip: "On that New York flight it is interesting, only the one leg is ultra-long. Now which is very funny, okay, here is why I have a problem, ultralong to this point, but to get back to my house which is in Johannesburg, I have to fly this other leg that is not ultralong, where you should look at the whole picture as one. You take what you want to be as ultra-long but the other you forget. And that other leg still affects me, so this is where I can't agree with you say "okay I will take this, but I will forget about this" (Group 3, H). One of the most frequent suggestions for reducing fatigue during ULR trips was to also split the rest breaks on the shorter inbound leg. Another suggestion related to the location of designated rest seats, with participants highlighting the importance of being able to sit away from passengers during their rest opportunity: "On the New York and Beijing flight, the airline has booked off seats for the crew, but those seats can be anywhere. Sometimes they are right in the middle of two passengers [...] you cannot sit and have your catnaps there in the middle of passengers and whatever. It needs to be a secluded area or it needs to be a business class seat like they do for the cockpit" (Group 1, E).

Layover factors contributing to fatigue included having to wait to access the hotel room, the hotel being in a noisy location, and the time and effort needed to access amenities in the area. However, participants also indicated that the layover's destination could influence the amount of time spent on rest versus recreation: "It's New York. You not gonna just sit in your room and you want to go out and you want to go and explore and we do, it's how we roll" (Group 3, B).

Participants' recommendations for improving rest are summarized in Fig. 1 under 'Strategy 1', 'Strategy 4', and 'Strategy 5'.

\section{Workload}

Workload was also considered to cause fatigue. Identified factors increasing workload included the range of duties and staffing levels on the aircraft, demands and complaints of passengers, and the service expectations of the company. On flights operating with minimum crew, or with a shortage of crew as a result of crewmembers being sick, workload was a major issue, particularly when the delivery of service to passengers was already under time pressure: "And cutting down the manpower, that has changed our work environment; the load on per person has increased because of that. Like with the Durban trying to do it with 2 people with the 800, we used to be 3 and we are working with people short now and therefore the workload is a lot more, and sometimes, through nobody's fault, people book off and then there is no people to go around and therefore we fly crew members short and those flights are demanding as well. On top of the people that they took away originally that we used to have, and this extra person who did not show up for that flight, that we have to do without, that is exhausting" (Group 2, C). Participants argued that having additional crewmembers on board would reduce their workload, which in turn would improve their subsequent rest or increase the time available for in-flight rest.

Participants' recommendations for better managing workload are summarized in Fig. 1 under 'Strategy 2'.

\section{Work environment}

Participants also felt that their work environment increased fatigue, particularly aspects of their physical work environment, work resources, and collegial support. Working in a pressurized cabin with lower oxygen (airflow) levels was considered fatiguing and some participants suggested that the flight crew were responsible for lower oxygen or airflow levels in the cabin. The cold environmental temperature in the galleys was thought to increase crewmembers' energy expenditure, thus contributing to their fatigue. This problem was identified as being related to the 
Airbus aircraft. Problems with work resources included the malfunctioning of equipment as a source of stress contributing to fatigue, and the lack of healthy food on board: "It is rare to find a healthy meal on board and sometimes we find ourselves pushed to eat whatever there is available there to eat, and eventually that I think affects our bodies and we cannot perform, and we get tired because we ate too much [...] you know all the time they [the cockpit crew] get fruit overseas and you ask yourself why don't we have fruit as cabin crew? We are the ones that are actually burning the energy most; we need healthy food on board" (Group 2, A). Colleagues could have a negative or a positive impact. Fatigue was linked to other team members "not pulling their weight". On the other hand, the benefit of having collegial support was also highlighted, with others picking up and helping when someone struggled with fatigue.

Participants' recommendations for improving the work environment are summarized in Fig. 1 under 'Strategy 3', while supporting staff wellbeing is listed under 'Strategy 4'.

\section{Company support}

Across all three groups, company support was raised as an important factor affecting fatigue at work and participants pointed out several areas where they felt support was lacking and/or could be improved.

Firstly, there was a general consensus that flight crew and cabin crew are treated as two separate cultures within the company, even though cabin crew are seen as facing the same fatigue-related challenges as flight crew. Participants listed numerous examples of better conditions for flight crew with regards to rest provisions, the quality of the work environment and resources such as food in-flight: "they can fly a maximum of 1,000 $h$ in a year, and we don't have a limit. This is it, and then you are trying to merge two systems together, two different, to get an outcome. It doesn't work. That is why I say it's also putting systems that are not talking, not compatible. They have got more rest because there are two on and the other two off. So they will have more rest period than normal cabin crew" (Group 3, H).

Secondly, the communication between management and cabin crew was considered an issue. This included the company informing cabin crew about delays: "and another issue is that whenever there is a delay, they never inform us, we can stay here for 3 or $4 \mathrm{~h}$ whereas the flight deck crew they know about it. We will come in fresh and by the time we start to operate we are tired because we have been sitting there for 3 or $4 \mathrm{~h}$ and then,
I don't know if we are not important or what, but they tend to focus on the flight deck crew. They give them most of the information but they don't give us anything, so that is what they need to work on as well" (Group 2, B). Management's lack of effort to understand the challenges that cabin crew encounter was also raised: "In any company you should have all the role players knowing what is going on, on the other side [...] what I am saying is that our management needs to know first-hand what, how fatigue affects us and it is such things that can make change more effective and quicker" (Group 2, J).

Thirdly, several participants discussed emotional and/ or physical wellbeing as factors in fatigue. Some felt that it was not easy to book off sick, while another participant found it difficult to book annual leave when needed. Some felt that the company did not provide a career path for cabin crew, while others described a lack of appreciation or recognition from the company: "we are always on our toes and when you come down with flu or severe flu or something or a cold, they expect you to be at work [agreement from the group]. Should you book off, it is another thing [cross talk]. That's why people tend to fall asleep..." (Group 1, D).

Lastly, a number of participants also felt that the company 'will not go the extra mile', such as not paying for early access to the hotel room to help increase the crews' sleep opportunity, and not prioritizing improving facilities for sleep. For example, one participant commented on the lack of facilities for cabin crew on standby at the airport: "The facilities here at the standby room, it's non-existing. You are sitting there, if you 're there in the morning there is nothing for you, if you are there after 2 o'clock in the afternoon you can't have lunch or anything else because the cafeteria closes at 2 o'clock or 1.30 somewhere there. If you are here over weekends there is absolutely no support for you" (Group 1, E). Participants therefore suggested a clear and effective support structure to help minimize fatigue and stress and improve productivity. See 'Strategy 4' in Fig. 1.

\section{Fatigue management training}

Participants rated highly the safety training they received, but felt that the fatigue management training was inadequate - an informative forum rather than actual training. Safety training was viewed as very helpful when working fatigued, because of the skills acquired to work effectively as a team. Participants therefore suggested that the company provide a fatigue management course with an assessment component that cabin crew are required 
to pass: "Simple, I think instead of a lot of the courses that the company is running that must start to introduce a fatigue management course, to make sure that every crew member, maybe once goes into that course. Instead of [inaudible] all these other courses, but I think it is the time now the company to start this an important thing, fatigue management, it must be a course that a crew member should pass [inaudible] must be trained about fatigue management" (Group 2, G). Ab initio training (the initial training that cabin crew undergo) was strongly supported for cabin crew and all relevant personnel, including the company's medical staff and managers. Participants' recommendations for improving fatigue management training are included in Fig. 1 under 'Strategy 5'.

\section{Self-management of fatigue}

When asked about managing their fatigue at home and at work, participants not only talked about the strategies they utilize, but also shared personal views on this topic. Fatigue management was viewed as a shared responsibility between the company and cabin crew, but they also indicated that the management of fatigue was under-estimated, or 'easier said than done'. They also highlighted the need for a work-life balance: "Just everyday life, you also are trying to keep a balance in your life, trying to, as a crew member, trying to have a normal life at home, whereas you also have your responsibilities towards your family and your friends and you are trying to keep up with the housework and cooking and it adds up and also basically you need your rest for your flights as well, so it takes up a lot of time" (Group 3, B).

Sleep was the primary strategy utilized for managing fatigue at home, at work and on layover. Participants also talked about taking naps in preparation for a flight, in flight, in the car before driving home and/or at home upon arrival following an international flight: "Some people sit and sleep in the car park for a while just to get over that very, very tiredness you know until they can safely drive home because not all of us stay close" (Group 1, B). Having better standby provisions at the airport would also be beneficial for taking naps.

Strategies for promoting sleep included the use of sleeping aids such as drinking hot milk, listening to classical music, reading before bed, taking a sleeping tablet or consuming alcohol, and creating a sleep conducive environment by turning one's phone off, keeping noise to a minimum, darkening the room, and/or sleeping with an electric blanket on. Exercise before sleep was also considered beneficial for promoting sleep.
Strategies for keeping alert at work included keeping busy, making conversation, drinking plenty of water and caffeinated beverages. Receiving support from colleagues was also considered helpful. In addition, participants talked about the benefits of having a healthy lifestyle, including regular exercise and a healthy diet, to help manage their fatigue but acknowledged that this in itself was not sufficient. Participants' recommendations for improving cabin crews' self-management of fatigue are listed in Fig. 1 under 'Strategy 6'.

\section{Discussion}

The present study has improved our understanding of cabin crew perceptions of the causes of their fatigue and how fatigue might affect safety and their job performance, particularly in the context of ULR operations.

Cabin crew participating in the present study identified a range of fatigue-related factors and made a number of suggestions for changes to help improve its management, which were summarized in six themes, namely insufficient rest, workload, work environment, company support, fatigue management training and self-managing fatigue.

The view that fatigue is inherent and inevitable due to the nature of their work is consistent with previous research $^{2,5,6,36)}$, as is the view that fatigue affects cabin crew health and wellbeing as well as safety (cabin, passenger and personal) and cabin service ${ }^{3)}$.

As well as having concerns about fatigue-related performance impairment at work, several participants reported having fallen asleep while driving home, thus increasing the risk of a motor vehicle accident ${ }^{37)}$. Pre-existing fatigue has been shown to increase the likelihood of the common cold, flu-like illness, and gastroenteritis ${ }^{38)}$. Chronic short sleep, and recurrent circadian disruption resulting from shift work have each also been associated with an increased risk for obesity, diabetes mellitus, hypertension, and cardiovascular disease ${ }^{39,40)}$. Furthermore, shiftwork has been associated with an increased risk of cancer ${ }^{40)}$, and the risk of breast cancer is higher among female cabin crew compared to other shiftworkers ${ }^{41)}$.

Given these potentially serious consequences, careful consideration should be given to all sources of cabin crew fatigue to enable more effective fatigue management. While the physiological causes of fatigue are sleep loss and circadian disruption ${ }^{2}$, participants also identified a range of additional contributing factors at work and outside of work, including: insufficient rest, high workload, the work environment, a lack of company support and 
insufficient fatigue management training. Most of these factors have been identified previously $1,3,5,6,9,42,43)$. However, the present study also highlights the importance of sufficient rest not only for obtaining adequate recovery sleep but also for achieving a work-life balance. It also highlights the need for company support to assist cabin crew with fatigue management.

\section{The importance of sufficient rest for a work-life balance}

Participants highlighted the need for a work/life balance, but that it could be difficult to allocate adequate time for rest and recovery as well as for family responsibilities, domestic tasks, social activities, community commitments, studying, and/or maintaining hobbies and there was generally a trade-off between sleep and other activities. Both male and female participants indicated that they would attend to family responsibilities and domestic tasks when at home during the day, suggesting that this issue is not gender-specific, but rather is driven by the nature of their work. Other studies have shown that long work hours and/ or family responsibilities are associated with obtaining insufficient sleep, irrespective of gender ${ }^{44,45)}$. Furthermore, shift workers are more likely to report difficulties combining work and life in comparison to day workers, particularly when work characteristics include minimum rest opportunities between periods of work, night shifts or weekend work ${ }^{46)}$. The work schedules of cabin crew flying long haul and ULR include all these characteristics, as well as frequent time zone changes. One study based on subjective sleepiness ratings suggests that cabin require an additional recovery day beyond the two needed for regular daytime workers and shift workers ${ }^{47)}$. Although fatigue risk management focuses specifically on safety, ideally it should also facilitate a work-life balance in support of employees' health and wellbeing, since "there is more to life than work and sleep" ${ }^{, 20,48,49)}$.

Participants in the present study indicated that due to competing time demands, their families could become a source of stress at home. In a study with train drivers working shift work, receiving family support was highlighted as the most important factor in the successful management of fatigue, although the train drivers felt that family members often did not have a good understanding of shift work and fatigue ${ }^{50)}$. There is evidence that involving family members in fatigue management training, or providing them with take-home resources can be valuable ${ }^{49)}$, and that the long-term value of training may be increased when there is ongoing support and reinforcement at home ${ }^{51)}$. This aspect was therefore added to Fig. 1 under Strategy 5.

In the present study, there was a strong consensus that rostering was not managed properly and that company support was inadequate. Where employees are dissatisfied with current rostering or other management and organisational issues, the effectiveness of fatigue management training may be reduced ${ }^{51)}$. On the other hand, fatigue management training can improve employees' understanding and perception of the rostering, the challenges associated with working irregular hours ${ }^{51)}$, and ameliorate any misconceptions about fatigue. Importantly, all personnel within an organisation need to understand that rostering alone cannot eliminate fatigue and should not be an organisation's only fatigue management strategy ${ }^{21)}$. It is therefore recommended that fatigue management training for cabin crew is evidence-based, requires assessment, and is given priority within an airline to not only educate cabin crew, but also provide a communication forum where cabin crew can share their experiences, voice any concerns and feel listened to ${ }^{52)}$.

\section{The importance of company support}

Taking a safety management systems approach, fatigue risk management focusses on the conditions under which individuals work that could give rise to fatigue-related errors. This also includes the working conditions that can influence the fatigue levels of crewmembers, such as the quality of rest facilities and availability of support staff ${ }^{21)}$. In the present study, there was a perceived lack of company support in terms of the provision of standby facilities at the airport, the quality of cabin crew rest facilities, the ability to take sick leave and annual leave, the quality of communication from management regarding operational issues such as flight delays, as well as management's engagement with cabin crew in general. Participants also considered the fatigue-related provisions for flight crew better than for cabin crew, even though cabin crew were seen as facing the same fatigue-related challenges.

Studies have shown that employees' perceived organisational support, which to a large extent is influenced by their working conditions ${ }^{53,54)}$, is positively correlated with safety-related behaviour, including upward safety communication ${ }^{55,56)}$. Hofmann and Morgeson ${ }^{55)}$ suggest that employees who perceive their company as caring for their wellbeing will more easily raise any safety concerns with their managers. In FRMSs, voluntary fatigue reporting by crewmembers is an essential source of fatigue monitoring data and should empower personnel to propose preventive and corrective actions for any fatigue-related issues ${ }^{21}$. In 
turn, management must provide feedback to their employees regarding any changes made in response to fatigue reports received ${ }^{21)}$. This form of communication should also improve crews' perceptions of organisational support and communication with management.

Furthermore, all personnel with direct or indirect influence on cabin crews' work, including senior management, need to have an appropriate understanding of fatigue through participation in fatigue management training programs $^{21)}$. Making crewmembers aware of management's engagement in all fatigue management activities may enhance cabin crews' perception of company support.

\section{Study limitations}

Although it is possible that participants self-selected into the study because fatigue is a major concern for them, the present findings corroborate previous research on cabin crew fatigue ${ }^{1-9)}$, suggesting that participating cabin crew were not suffering considerably more from fatigue than their colleagues. Each group tended to reach consensus about the issues even though every effort was made to ensure that all participants had the opportunity to be heard.

It should also be noted that $73 \%$ of the participants were male, whereas the proportion of male cabin crew at this airline was about $34 \%$ at the time of the study. It is therefore possible that the participants in this study are not entirely representative of their work force. Nevertheless, the richness of the conversation confirmed the usefulness of the focus group approach, which does not aim to provide a representative view.

Due to the qualitative nature of the study, the researcher's views and experience of fatigue inevitably influenced all aspects of the study which shaped the present findings.

Additional research may involve surveying cabin crew across the whole airline on the extent of their agreement/ disagreement with the views raised in the present study ${ }^{57)}$.

Despite these limitations, the study findings contribute to an increased understanding of the causes and consequences of cabin crew fatigue. Many of the key factors contributing to cabin crew fatigue that were identified in the present study have been reported previously ${ }^{1,3,5,6}$, $9,42,43)$. However, unlike previous studies, cabin crew in this study all had experience with ULR flights, for which FRMS processes were put in place by the airline to manage the associated fatigue risk. Nevertheless, they indicated that the management of fatigue was 'easier said than done', highlighting that sufficient rest was not only needed for obtaining adequate recovery sleep, but also for achieving a work-life balance. In addition, they also highlighted the importance of company support needed for improving the fatigue risk management of cabin crew.

\section{Recommendations}

Based on the present findings, it is recommended that airline operators consider the importance of sufficient rest for adequate recovery and for facilitating a work-life balance in support of employees' health and wellbeing. It is also recommended that airline operators consider the importance of company support, in the form of fatiguerelated processes and resources, effective communication and management's engagement with cabin crew in general. Fatigue management training and non-punitive fatigue reporting, both essential components of an FRMS, can ameliorate these gaps, in conjunction with the other fatigue risk mitigation strategies identified for improving cabin crews' safety and service, and health and wellbeing.

\section{Author Contribution}

MV and LS designed the study; MV collected the data and performed the thematic analysis. MV, LS and PG discussed and reviewed the themes. MV drafted the manuscript. All authors contributed to the interpretation of the findings, reviewed and edited the manuscript.

\section{Conflict of Interest}

All authors declare no conflict of interest.

\section{Acknowledgements}

The authors thank the cabin crew members who participated in this study. We gratefully acknowledge Wynand Serfontein, Fatigue Specialist, South African Airways for his permission to conduct this study and Masilo Matseke, Adhoc Service Trainer, Customer Standards and Training at South African Airways for his outstanding assistance on this project, including the recruitment of all research participants, assistance with facilitation of the focus groups and following up on release-of-transcript forms from participants. At Massey University, we gratefully acknowledge Tracy Sanderson at the Sleep/Wake Research Centre for transcribing the audio recordings; and Professor Antonia Lyons at the School of Psychology, for her expert advice and guidance on the data analysis. We also thank the three anonymous reviewers for critically reading the manuscript and providing helpful suggestions for improving its clarity. Financial and material support was provided 
by the Sleep/Wake Research Centre, Massey University, Wellington, New Zealand.

\section{References}

1) Avers KE, King SJ, Nesthus TE, Thomas S, Banks J (2009) Flight Attendant Fatigue, Part I: National Duty, Rest, and Fatigue Survey. DOT/FAA/AM-09/24, Office of Aerospace Medicine, Federal Aviation Administration, Washington DC, http://www.dtic.mil/dtic/tr/fulltext/u2/a520848.pdf. Accessed September 23, 2013.

2) Nesthus TE, Schroeder DJ, Connors MM, RentmeisterBryant HK, DeRoshia CW (2007) Flight Attendant Fatigue. DOT/FAA/AM-07/21, Office of Aerospace Medicine, Federal Aviation Administration, Washington DC, http:// www.dtic.mil/dtic/tr/fulltext/u2/a471470.pdf. Accessed September 23, 2013.

3) Avers KE, Nei D, King SJ, Thomas S, Roberts C, Banks J, Nesthus TE (2011) Flight Attendant Fatigue: A Quantitative Review of Flight Attendant Comments. DOT/FAA/AM11/16, Office of Aerospace Medicine, Federal Aviation Administration, Washington DC, http:/www.dtic.mil/dtic/ tr/fulltext/u2/a554063.pdf. Accessed September 23, 2013.

4) Holcomb K, Avers KE, Dobbins L, Banks J, Blackwell LV, Nesthus TE (2009) Flight Attendant Fatigue, Part IV: Analysis of Incident Reports. DOT/FAA/AM-09/25, Office of Aerospace Medicine, Federal Aviation Administration, Washington DC, Accessed September 23, 2013.

5) Castro M, Carvalhais J, Teles J (2015) Irregular working hours and fatigue of cabin crew. Work 51, 505-11. [Medline] [CrossRef]

6) Ono Y, Watanabe S, Kaneko S, Matsumoto K, Miyao M (1991) Working hours and fatigue of Japanese flight attendants (FA). J Hum Ergol (Tokyo) 20, 155-64. [Medline]

7) Lowden A, Åkerstedt T (1999) Eastward long distance flights, sleep and wake patterns in air crews in connection with a two-day layover. J Sleep Res 8, 15-24. [Medline] [CrossRef]

8) Lowden A, Åkerstedt T (1998) Sleep and wake patterns in aircrew on a 2-day layover on westward long distance flights. Aviat Space Environ Med 69, 596-602. [Medline]

9) MacDonald LA, Deddens JA, Grajewski BA, Whelan EA, Hurrell JJ (2003) Job stress among female flight attendants. J Occup Environ Med 45, 703-14. [Medline] [CrossRef]

10) Roma PG, Mallis MM, Hursch SR, Mead AM, Nesthus TE (2010) Flight Attendant Fatigue recommendation II: Flight Attendant work/rest patterns, alertness, and performance assessment. DOT/FAA/AM-10/22, Office of Aerospace Medicine, Federal Aviation Administration, Washington DC, http://www.dtic.mil/dtic/tr/fulltext/u2/a534695.pdf. Accessed September 23, 2013.

11) Hirshkowitz M, Whiton $K$, Albert SM, Alessi C, Bruni O, DonCarlos L, Hazen N, Herman J, Katz ES, KheirandishGozal L, Neubauer DN, O’Donnell AE, Ohayon M, Peever J,
Rawding R, Sachdeva RC, Setters B, Vitiello MV, Ware JC, Adams Hillard PJ (2015) National Sleep Foundation's sleep time duration recommendations: methodology and results summary. Sleep Health 1, 40-3. [Medline] [CrossRef]

12) Watson NF, Badr MS, Belenky G, Bliwise DL, Buxton OM, Buysse D, Dinges DF, Gangwisch J, Grandner MA, Kushida C, Malhotra RK, Martin JL, Patel SR, Quan SF Tasali E, Consensus Conference Panel (2015) Joint consensus statement of the American Academy of Sleep Medicine and Sleep Research Society on the recommended amount of sleep for a healthy adult: methodology and discussion. Sleep 38, 1161-83. [Medline] [CrossRef]

13) Atkinson G, Batterham AM, Dowdall N, Thompson A, van Drongelen A (2014) From animal cage to aircraft cabin: an overview of evidence translation in jet lag research. Eur J Appl Physiol 114, 2459-68. [Medline] [CrossRef]

14) Lowden A, Åkerstedt T (1998) Retaining home-base sleep hours to prevent jet lag in connection with a westward flight across nine time zones. Chronobiol Int 15, 365-76. [Medline] [CrossRef]

15) Härmä M, Laitinen J, Partinen M, Suvanto S (1994) The effect of four-day round trip flights over 10 time zones on the circadian variation of salivary melatonin and cortisol in airline flight attendants. Ergonomics 37, 1479-89. [Medline] [CrossRef]

16) Härmä M, Suvanto S, Partinen M (1994) The effect of four-day round trip flights over 10 time zones on the sleep-wakefulness patterns of airline flight attendants. Ergonomics 37, 1461-78. [Medline] [CrossRef]

17) Suvanto S, Härmä M, Ilmarinen J, Partinen M (1993) Effects of $10 \mathrm{~h}$ time zone changes on female flight attendants' circadian rhythms of body temperature, alertness, and visual search. Ergonomics 36, 613-25. [Medline] [CrossRef]

18) Vejvoda M, Samel A, Maaß H, Luks N, Linke-Hommes A, Schulze M, Mawet L, Hinninghofen H (2000) DLR Institute of Aerospace Medicine Köln, Germany, 1-142, https://www. researchgate.net/profile/N_Luks/publication/224791707 Untersuchungen_zur_Beanspruchung_des_ Kabinenpersonals_auf_transmeridianen_Strecken/ links/0046352fbd486e18b7000000.pdf. Accessed April 11, 2016.

19) Cabon P, Mollard R, Debouck F, Chaudron L, Grau J, Deharvengt S (2008) From flight time limitations to fatigue risk management systems. Proceedings of the Third Resilience Engineering Symposium, Presses des MINES, Antibes, Juan-les-Pins, France, 27-34.

20) Gander P, Hartley L, Powell D, Cabon P, Hitchcock E, Mills A, Popkin S (2011) Fatigue risk management: organizational factors at the regulatory and industry/ company level. Accid Anal Prev 43, 573-90. [Medline] [CrossRef]

21) International Civil Aviation Organization (2016) Manual for the oversight of fatigue management approaches. ICAO, Montréal, Canada, http://www.icao.int/safety/ 
fatiguemanagement/frms $\% 20$ tools/doc $\% 209966 \% 20-\% 20$ frms $\% 20$ manual $\% 20$ for $\% 20$ regulators.pdf. Accessed April 11, 2016.

22) Flight Safety Foundation (2005) Fourth workshop yields insights into early ultra-long-range operations. Flight Saf Dig 24, 1-15.

23) van den Berg MJ, Signal TL, Mulrine HM, Smith AAT, Gander PH, Serfontein W (2015) Monitoring and managing cabin crew sleep and fatigue during an ultra-long range trip. Aerosp Med Hum Perform 86, 705-13. [Medline] [CrossRef]

24) van den Berg MJ, Signal TL, Gander PH (2015) Greater subjective workload is associated with higher cabin crew fatigue on ULR flights. Sleep 38, A87.

25) Damos DL, Boyett KS, Gibbs P (2013) Safety versus passenger service: the flight attendants' dilemma. Int J Aviat Psychol 23, 91-112. [Medline] [CrossRef]

26) Hagihara A, Tarumi K, Nobutomo K (2001) The number of steps taken by flight attendants during international longhaul flights. Aviat Space Environ Med 72, 937-9. [Medline]

27) Samel A, Vejvoda M, Maßß H (2002) Workload in cockpit and cabin crew during transmeridian flight. Aviat Space Environ Med 73, 274.

28) Glitsch U, Ottersbach HJ, Ellegast R, Schaub K, Franz G, Jäger M (2007) Physical workload of flight attendants when pushing and pulling trolleys aboard aircraft. Int J Ind Ergon 37, 845-54. [CrossRef]

29) van den Berg MJ (2016) Fatigue management developments for cabin crew, FMAS 2016. International Civil Aviation Organisation, Montréal, Canada, Powerpoint presentation, 1-21, https:/www.icao.int/Meetings/fmas/ Documents/Presentations/Margo\%20VandenBerg_FM\%20 Developments\%20for\%20Cabin\%20Crew.pdf.

30) Hennink MM (2007) International focus group research: a handbook for the health and social sciences. Cambridge University Press, New York.

31) Braun V, Clarke V (2013) Successful qualitative research: a practical guide for beginners. Sage, London.

32) Maurino D (2017) Why SMS: an introduction and overview of safety management systems. Discussion Paper 2017-16, International Transport Forum, Paris, 1-61.

33) Morgan DL (2007) Paradigms lost and pragmatism regained methodological implications of combining qualitative and quantitative methods. J Mixed Methods Res 1, 48-76. [CrossRef]

34) Braun V, Clarke V (2006) Using thematic analysis in psychology. Qual Res Psychol 3, 77-101. [CrossRef]

35) Tracy SJ (2010) Qualitative quality: eight "big-tent" criteria for excellent qualitative research. Qual Inq 16, 837-51. [CrossRef]

36) Vejvoda M, Samel A, Maaß H, Luks N, Schulze M, Mawet L (2001) Study on strain, workload, and circadian rhythm in cabin crews during transmeridian flights. Aviat Space Environ Med 72, 289.

37) Bioulac S, Micoulaud-Franchi JA, Arnaud M, Sagaspe P,
Moore N, Salvo F, Philip P (2017) Risk of motor vehicle accidents related to sleepiness at the wheel: a systematic review and meta-analysis. Sleep 40, zsx134-134. [Medline] [CrossRef]

38) Mohren DC, Swaen GM, Kant IJ, Borm PJ, Galama JM (2001) Associations between infections and fatigue in a Dutch working population: results of the Maastricht cohort study on fatigue at work. Eur J Epidemiol 17, 1081-7. [Medline] [CrossRef]

39) Itani O, Jike M, Watanabe N, Kaneita Y (2017) Short sleep duration and health outcomes: a systematic review, metaanalysis, and meta-regression. Sleep Med 32, 246-56. [Medline] [CrossRef]

40) Abbott SM, Malkani RG, Zee PC (2017) Circadian dysregulation in mental and physical health. In: Principles and practice of sleep medicine, Kryger M, Roth T and Dement W (Eds.), 405-413, Elsevier, Philadelphia.

41) He C, Anand ST, Ebell MH, Vena JE, Robb SW (2015) Circadian disrupting exposures and breast cancer risk: a meta-analysis. Int Arch Occup Environ Health 88, 533-47. [Medline] [CrossRef]

42) Wahlstedt K, Lindgren T, Norbäck D, Wieslander G, Runeson R (2010) Psychosocial work environment and medical symptoms among Swedish commercial airline cabin crew. Am J Ind Med 53, 716-23. [Medline]

43) Bergman A, Gillberg G (2015) The cabin crew blues: middle-aged cabin attendants and their working conditions. Nordic J Working Life Stud 5, 23-39. [CrossRef]

44) Skinner N, Dorrian J (2015) A work-life perspective on sleep and fatigue-looking beyond shift workers. Ind Health 53, 417-26. [Medline] [CrossRef]

45) Barnes CM, Wagner DT, Ghumman S (2012) Borrowing from sleep to pay work and family: expanding time-based conflict to the broader nonwork domain. Person Psychol 65, 789-819. [CrossRef]

46) Karhula K, Puttonen S, Ropponen A, Koskinen A, Ojajärvi A, Kivimäki M, Härmä M (2017) Objective working hour characteristics and work-life conflict among hospital employees in the Finnish public sector study. Chronobiol Int 34, 876-85. [Medline] [CrossRef]

47) Åkerstedt $\mathrm{T}$, Kecklund G, Gillberg M, Lowden A, Axelsson J (2000) Sleepiness and days of recovery. Transp Res, Part F Traffic Psychol Behav 3, 251-61. [CrossRef]

48) Costa $G$ (2004) Multidimensional aspects related to shiftworkers' health and well-being. Rev Saude Publica 38 Suppl, 86-91. [Medline] [CrossRef]

49) Lerman SE, Eskin E, Flower DJ, George EC, Gerson B, Hartenbaum N, Hursh SR, Moore-Ede M, American College of Occupational and Environmental Medicine Presidential Task Force on Fatigue Risk Management (2012) Fatigue risk management in the workplace. J Occup Environ Med 54, 231-58. [Medline] [CrossRef]

50) Holland DW (2006) The effect of shiftwork related fatigue on the family life of train operators: implications for safety and health professionals. Work 26, 115-21. [Medline] 
51) Kerin A, Aguirre A (2005) Improving health, safety, and profits in extended hours operations (shiftwork). Ind Health 43, 201-8. [Medline] [CrossRef]

52) Gander PH, Marshall NS, Bolger W, Girling I (2005) An evaluation of driver training as a fatigue countermeasure. Transp Res, Part F Traffic Psychol Behav 8, 47-58. [CrossRef]

53) Kurtessis JN, Eisenberger R, Ford MT, Buffardi LC, Stewart KA, Adis CS (2017) Perceived organizational support: a meta-analytic evaluation of organizational support theory. J Manage 43, 1854-84.

54) Rhoades L, Eisenberger R (2002) Perceived organizational support: a review of the literature. J Appl Psychol 87, 698-714. [Medline] [CrossRef]

55) Hofmann DA, Morgeson FP (1999) Safety-related behavior as a social exchange: the role of perceived organizational support and leader-member exchange. J Appl Psychol 84, 286. [CrossRef]

56) Kath LM, Marks KM, Ranney J (2010) Safety climate dimensions, leader-member exchange, and organizational support as predictors of upward safety communication in a sample of rail industry workers. Saf Sci 48, 643-50. [CrossRef]

57) Gander P, Mangie J, Phillips A, Santos-Fernandez E, Wu LJ (2018) Monitoring the effectiveness of fatigue risk management: a survey of pilots' concerns. Aerosp Med Hum Perform 89, 889-95. [Medline] [CrossRef]

58) Moore-Ede M (2009) Evolution of fatigue risk management systems: the "tipping point" of employee fatigue mitigation. CIRCADIAN white paper. www.circadian.com/pages/157 white_papers.cfm. Accessed July 20, 2017. 